\title{
Challenges of Endocrinology Practice in Nigeria: Four Illustrative CASES
}

\section{F. O. Anumah}

Endocrine Unit, Department of Medicine, Ahmadu Bello University Teaching Hospital, Zaria, Nigeria Reprint requests to: Dr. F. O. Anumah, Department of Medicine, Ahmadu Bello University Teaching Hospital, Zaria, Nigeria

\begin{abstract}
In developing countries, like Nigeria, non-communicable diseases including endocrine disorders are on the increase. However, not much attention is paid to this group of diseases because of the enormous burden posed by infections. Despite this threat, endocrine disorders still constitute a significant cause of morbidity and mortality. The appropriate and gratifying practice of endocrinology requires skilled personnel, adequate investigative facilities and treatment modalities including: medical, surgical, hormonal and radiotherapy. Majority of the patients with endocrine diseases present to the nonspecialists, though they make a great impact, they have their limitations. Four endocrine cases are presented here to demonstrate the challenges posed by the dearth of facilities and the nonaffordability of appropriate treatment modality by the patients in most centers where endocrinology is practiced in Nigeria.
\end{abstract}

Key words: Endocrinology, challenges, Nigeria

\begin{abstract}
Résumé
Dans les pays en voie de développement, comme le Nigéria, les maladies non transmissibles, y compris les troubles endocriniens sont en hausse. Cependant, pas beaucoup d'attention est accordée à ce groupe de maladies en raison de l'énorme fardeau posé par les infections. Malgré cette menace, troubles endocriniens constituent toujours une cause importante de morbidité et de mortalité. La pratique appropriée et encourageant de l'endocrinologie nécessite du personnel qualifié, des installations adéquates d'enquête et les modalités de traitement, y compris médical, chirurgical, I'hormonothérapie, et la radiothérapie. La majorité des patients atteints de maladies endocriniennes se présentent aux non-spécialistes, quoiqu'ils fassent une grande influence, ils ont leurs limites. Quatre cas d'endocriniens sont présentés ici pour montrer les défis posés par la pénurie d'installations et du non accessibilité financière de la modalité de traitements appropriés pour les patients dans la plupart des centres où on fait le pratique d'endocrinologie an Nigéria.
\end{abstract}

Mots clés: Endocrinologie, les défis, le Nigéria

\section{Introduction}

Endocrine diseases with varied systemic manifestations are common worldwide. In many developing countries like Nigeria, non-communicable diseases including endocrine disorders are on the increase. ${ }^{1,2}$ However, not much attention is paid to this group of diseases because of the enormous burden posed by infections like malaria, tuberculosis and HIV/AIDS. ${ }^{3,4}$ Despite this threat by infections, endocrine disorders still constitute a significant cause of morbidity and mortality. The appropriate and gratifying practice of endocrinology requires adequate clinical skill, adequate facilities for various investigations and treatment modalities including: medical, surgical, hormonal and radiotherapy. 
There are less than 60 trained endocrinologists for a population of more than 140 million people and most of them are in the tertiary health care centers in the cities. Majority of the patients present to the nonspecialists, though they make a great impact, they have their limitations. Thus, the availability of skilled personnel for accurate clinical diagnosis, investigative facilities and affordability of treatment by the patients pose a great challenge in most centers where endocrinology is practiced in Nigeria. This report highlights some of these challenges as using 4 case illustrations in our endocrine practice in Zaria, Nigeria.

\section{Case 1 (Figure 1)}

A 56-year-old male mechanic has had diabetes mellitus and hypertension for 20 years. His diabetic control was never optimal at any point in time due to financial constraints. Seven years ago he developed gangrene of the right foot and had a bellow knee amputation (BKA). Four years later he presented for the first time in our center with gangrene of the left foot and poor diabetic control for which he had another BKA and became a bilateral amputee. This is the most devastating of the diabetic complications and has tremendous ramifications for the quality of life of the person with diabetes. In addition he had developed other chronic complications of diabetes such as: background diabetic retinopathy, diabetic nephropathy and ischemic heart disease. Due to his predicament, he lost his source of livelihood as a mechanic. He is still being followed up in the clinic but drug compliance is quite poor since he depends on goodwill for his sustenance and medical care.

\section{Case 2 (Figure 2)}

A 17-year-old female secondary school student whose parents are of low socio-economic group. She presented with a one- year history of goitre and symptoms of thyrotoxicosis. On examination, she had a diffuse soft goiter with a bruit, florid features of thyroid toxicity with ophthalmopathy. A diagnosis of grave's disease was made which was confirmed by abnormal thyroid function tests. She was subsequently commenced on antithyroid drugs and steroid therapy. She left the hospital for alternative medical treatment in the village. While there, the symptoms of thyroid disease and eye symptoms worsened and she reappeared to us in the endocrine clinic a year later with bilateral severe exposure keratitis, corneal opacity and unfortunately bilateral blindness. We recommenced antithyroid therapy and as at present has been rendered euthyroid. However, she requires decompressive eye surgery and possible corneal grafting for the eyes to be salvaged. This is almost an impossible task because of the low socioeconomic status of the parents of the patient.
Figure 1. Case 1

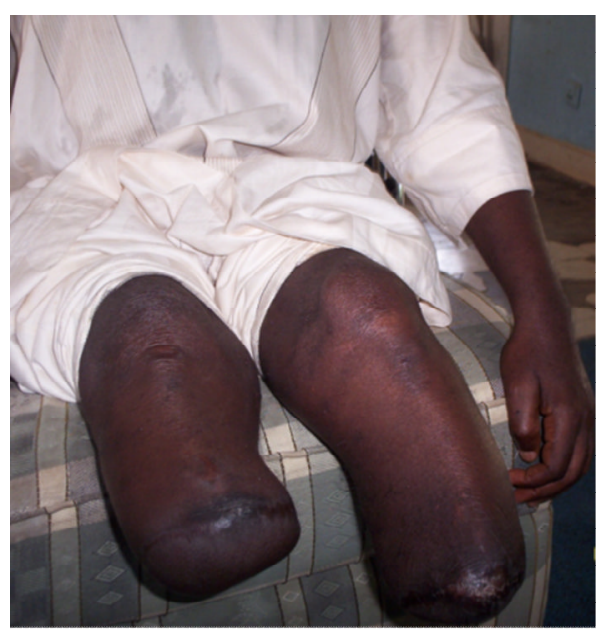

Figure 2. Case 2

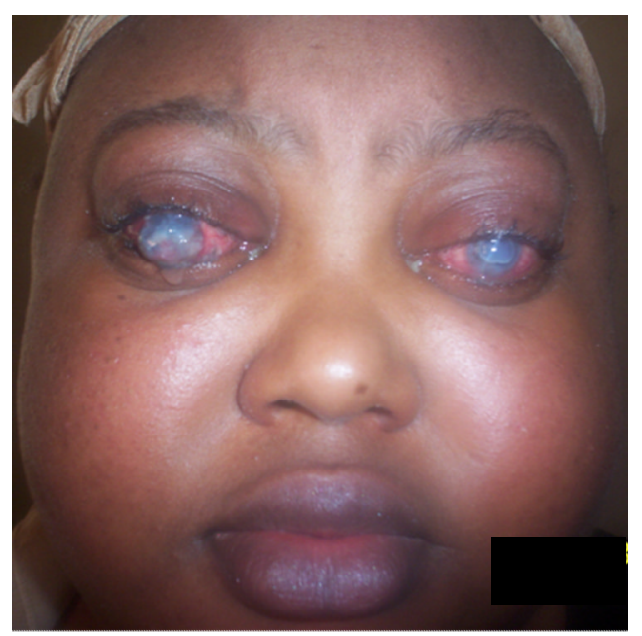

\section{Case 3 (Figure 3)}

A 20-year-old male secondary school student with recurrent abdominal pain for about 10 years for which he had only antispasmodics in the hospitals where he was attending. He was diagnosed diabetic 5 years earlier and was placed on insulin therapy. His parents, however, opted for alternative medical treatment. He came to us with symptoms of poor diabetic control and diarrhea. On examination, he was short for his age with a height of $1.35 \mathrm{~m}$, weight of $17 \mathrm{Kg}$ and a body mass index (BMI) of $9.3 \mathrm{~m} / \mathrm{kKg}^{2}$. $\mathrm{He}$ was bald, had tinea vesicolor on the skin, clinical and laboratory features of severe malnutrition, multiple vitamin deficiency, anemia, and evidence of chest infection. He also had $x$-ray features of pancreatic calcifications. A diagnosis of pancreatic diabetes was made. He was commenced on insulin therapy, multiple vitamin replacement, and high protein diet, antifungal and antibiotic therapy. He improved remarkably while in the ward, added $3 \mathrm{~kg}$ 
to his weight, scalp hair started growing and his diabetes became controlled. Both patient and parents were counseled and discharged for follow up in the diabetes clinic. He has, however, been lost to follow up for now.

\section{Case 4 (Figure 4)}

A 45-year-old house wife with a 4- year history of progressive increase in weight, the size of her hands and feet, excessive oiliness of the skin and separation of her teeth. She also had a gradual increase in the size of her breasts with lactation, amenorrhea and progressive deterioration of her vision. She was diagnosed hypertensive one and half years earlier. She developed features of congestive cardiac failure for 6 weeks prior to presentation. Examination revealed coarse facial features, a body mass index (BMI) of $35 \mathrm{Kg} / \mathrm{m} 2$, lactating breasts and bitemporal hemianopia. She was in congestive cardiac failure with a mitral regurgitation murmur. A diagnosis of acromegaly with acromegalic cardiomyopathy was made. Hormonal assays showed hyperprolactinaemia and unsuppressed growth hormone levels during oral glucose tolerance test, while the skull $x$-ray revealed erosion of the glenoid processes and the floor of the pituitary fossa. She was subsequently managed with anti cardiac failure drugs and dopamine agonistbromocriptine. She took bromocriptine erratically and was unable to afford the other modalities of treatment of the disease such as surgery or radiotherapy, and has since been lost to follow up.

Figure 3. Case 3

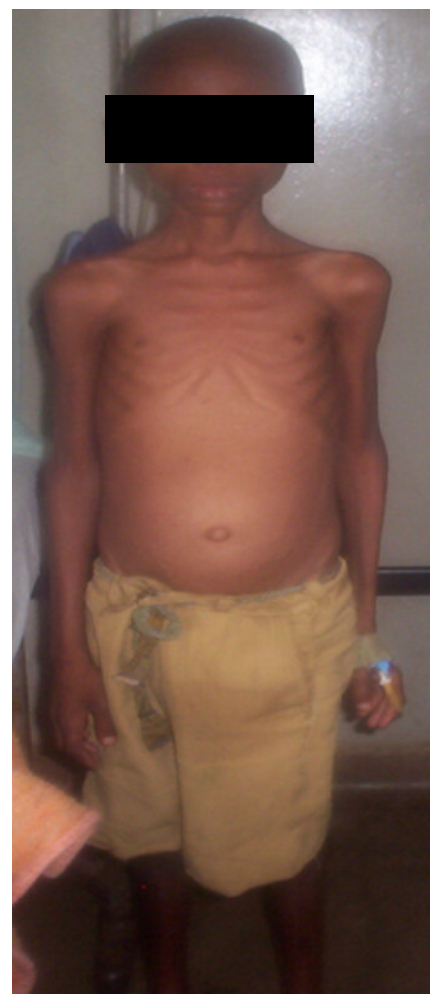

Figure 4. Case 4

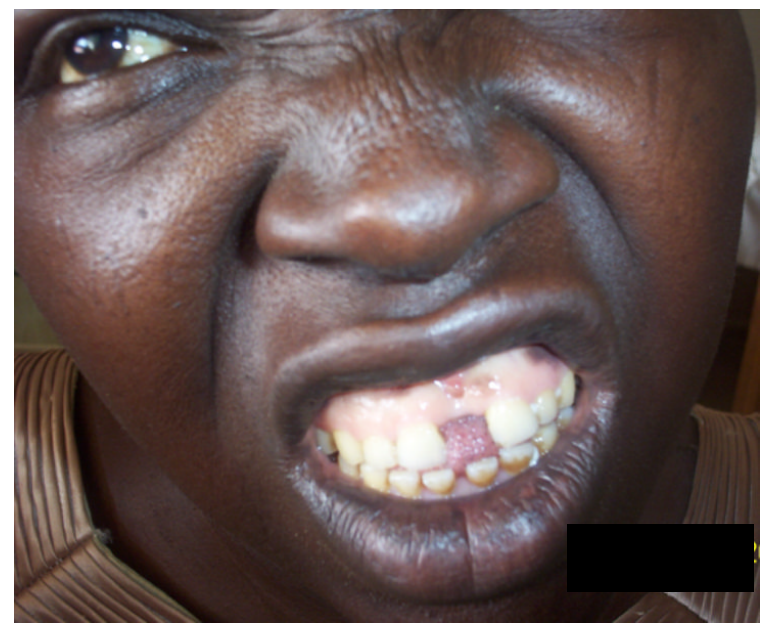

\section{Discussion}

The first case illustrates the vicious cycle of poverty, poor diabetic control, diabetic complications and outcome in the management of diabetes mellitus ${ }^{6}$ in a developing country. Because of poverty, adequate control was beyond his reach, resulting in loss of his limbs among other complications. Also, the nonavailability of proper prosthesis contributed to the loss of his livelihood. Unless such a patient gets help from the health care system, the future is bleak for this middle aged Nigerian.

In the second case presented, poverty again, ignorance, the menace of untrained alternative caregivers and the unavailability of affordable treatment modalities for her complications, have rendered her future bleak. ${ }^{6}$ Appropriate knowledge of her disease condition by her would have ensured a better outcome.

It is clear in the third case, that poverty was not the issue. Here, ignorance was the key factor. They sort orthodox medical care, but each time, he gets lost to follow up for alternative medication. He had pancreatic diabetes which was not diagnosed initially because of the limitations of the initial managing doctor, stressing the need for more specialists in the field of endocrinology.

Due to the nature of the presentation of the disease in case four, the diagnosis was not made until when she finally presented to the tertiary health care center with florid features and complications. Since the patient could not afford investigations like CT scan, we had to do with a skull x-ray. Growth hormone assays had to be done $1000 \mathrm{~km}$ away from the center where the patient was and the cost was not borne by her, for the objective diagnosis of acromegaly to be made. Although acromegaly is not common, the patient had symptoms unrecognized for four years which is the usual situation in this disease. ${ }^{7}$ Available treatment options ${ }^{8}$ were also too 
expensive for her, even bromocriptine therapy was irregular. Expertise for pituitary surgery and radiotherapy is also not in abundance.

\section{Conclusion}

Management of endocrine disorders can be quite rewarding in the right setting. Four case illustrations have been used to show the devastating effects of ignorance, poverty, the dearth of trained personnel in endocrine diseases and availability of investigative and treatment facilities. There is no support by the system which is a cash and carry system. Therefore the affordability of appropriate treatment modality in centers where they are available has greatly hindered the impact of endocrine practice on the Nigerian population.

\section{Recommendations}

There is a great need for patients' education on health care at community level, at schools and at hospital level since a patient who is knowledgeable is likely to comply with treatment and make better decisions concerning his health.

There is a definite need to train more endocrinologists for a population of over 140 million and have a few centers selected and well equipped for training and treatment purposes.

Mandatory continuous medical education of medical personnel on appropriate diagnosis, early and efficient intervention practices will go a long way in improving outcome. It is hoped that National Health Insurance Scheme (NHIS) effectively in place may offer affordable health care which will go a long way in improving the management outcome of endocrine diseases in Nigeria.

\section{References}

1. Akinkugbe 00. Non-communicable diseases in Nigeria: the next epidemic. Niger J Clin Pract. 2000;3:904-907.

2. Kadiri S. Tackling cardiovascular disease in Africa. BMJ 2005; 331: 711-2.

3. UNAIDS/WHO AIDS epidemic update: December 2005.

4. Snow R, Guerra C, Noor A, Myint H, Hays S. The global distribution of clinical episodes of plasmodium falciparum malaria. Nature. 2005;434:214-217.

5. American Diabetes Association. Clinical practice Recommendations 2002; 15: 398-402.

6. Abraham-Nordling $M$, Torring $O$, Hamberger $B$, et al. Grave's disease: a long-term quality -of- life follow up of patients randomized to treatment with antithyroid drugs, radioiodine, or surgery. Thyroid. 2005;15:1279-1286.

7. Mestron A, Webb SM, Astorga R, et al. Epidemiology, clinical characteristics, outcome, morbidity and mortality in acromegaly based on the Spanish Acromegaly Registry (Registro Espanol de Acromegalia, REA). Eur J Endocrinol. 2004;151:439-446.

8. Giustina A, Barkan A, Casanueva FF, et al. Criteria for cure of acromegaly: a consensus statement. J Clin Endocrinol Metab. 2000;85:526-529. 